\title{
BELA BADERNA - UMA ANÁLISE APÓCRIFA DA OBRA
}

\author{
English Title: BEAUTIFUL TROUBLE - AN APOCRYPHAL ANALYSIS OF THE \\ WORK
}

\section{doi>10.33726/akdpapers2447-7656v13a82022p17-40}

\section{PESSOA, Marcelo ${ }^{1}$ - (iD) https://orcid.org/0000-0002-9193-4604}

RESUMO: Bela Baderna - ferramentas para revolução", é um livro, cujo título original é Beautiful Trouble: A Toolbox For Revolution (2012), foi traduzido e publicado pela Ideal Edições (2013). Uma versão resumida da obra foi coeditada pela Escola de Ativismo, fragmentada e colocada ao livre acesso público em seu site. No início de 2022, o título em português se encontra esgotado para compra e, neste sentido, retiramos do site da Escola de Ativismo a versão desmontada do livro, o repaginamos e, a ele, acrescentamos mais um Capítulo, lá intitulado "Bela Apresentação Subvertida". E é este novo Capítulo, que se transformou na presente análise, ligeiramente adaptada à tipologia textual que aqui se exige nesta Revista. Por meio de uma revisão aplicada de expressões e de conceitos socioculturais que transitam nas redes sociais e na mídia jornalística, em suas diversas plataformas, trazemos ao conhecimento do leitor uma série de informações que, num contexto político-eleitoral efervescente, tal qual o que teremos em 2022, torna a leitura deste Artigo de análise, tão necessária quanto a leitura das páginas de Bela Baderna per se.

PALAVRAS-CHAVE: Bela Baderna, Beautiful Trouble, Produção e Difusão do Conhecimento

ABSTRACT: Beautiful Trouble - tools for revolution", is a book, whose original title is Beautiful Trouble: A Toolbox For Revolution (2012), was translated and published by Ideal Edições (2013). An abridged version of the work was coedited by School of Activism, fragmented and made available to the public on its website. At the beginning of 2022, the title in Portuguese is sold out for purchase and, in this sense, we removed the disassembled version of the book from the School of Activism website, we repackaged it and, to it, we added another Chapter, there entitled "Beautiful Subverted Presentation". And it is this new Chapter, which has become the present analysis, slightly adapted to the textual typology required here in this Journal. Through an applied review of expressions and sociocultural concepts that transit in social networks and in the journalistic media, in their various platforms, we bring to the reader's attention a series of information that, in an effervescent political-electoral context, such as what we will have in 2022, makes reading this analysis article as necessary as reading the pages of Beautiful Trouble per se.

KEYWORDS: Beautiful Trouble, Bela Baderna, Production and Dissemination of Knowledge

\footnotetext{
${ }^{1}$ Bolsista de Produtividade Científica - Chamada 01/2021 - Programa de Bolsas de Produtividade em Pesquisa - PQ / UEMG.
} 


\section{AKED』A}

\section{INTRODUÇÃO}

O livro Beautiful Trouble - a toolbox for Revolution, publicado em 2012, tem 450 páginas. Em sua tradução para o português, (Ideal Edições, 2013), foi "resumido" para uma edição pocket, e passou a se chamar Bela Baderna - ferramentas para revolução.

Em 2016, a Escola de Ativismo, entidade de ativismo social brasileira, desmontou o miolo da obra, retirou o Posfácio da Edição Brasileira, e dispôs em seu site, os capítulos traduzidos e resumidos, dando-lhes livre acesso ao público em geral (https://medium.com/@EAtivismo/bela-baderna-ferramentas-para-

revolu\%C3\%A7\%C3\%A3o-f5b266d4d559. Acesso em 07/01/2022, às 16h48min). E, é a partir disto, que nesta republicação de 2022 , faremos, antes da análise da obra propriamente dita, três considerações.

Em primeiro lugar, consideramos que pode ter havido uma subversão na tradução do título, o que pode ter contribuído para que a ideia original de uma "Caixa de Ferramentas", cujos itens até seriam capazes de colaborar cientificamente com a oferta de "objetos de estudo" para uma tomada de consciência sobre a transformação do comportamento e do pensamento na sociedade, perdessem a sua "aura" de Ciência e ficassem à mercê de quaisquer interpretações.

Esse deslize linguístico pode ter ajudado, portanto, parte da militância mais aguerrida na operação de um malabarismo interpretativo da obra, fazendo com que eventuais postulados teóricos que dela pudessem ser extraídos, virassem, em suas 


\section{AKED』A}

mãos, meros compilados de "Métodos para a Organização Coreográfica da Bagunça" ou para o estabelecimento de uma "Nova (Des)Ordem Mundial":

Quer dizer: como chamar a atenção para uma causa, ou conseguir provocar um debate, ou conquistar determinado público, fazendo exatamente aquilo que se espera que façamos? Como mudar o jogo com ferramentas e estratégias que já foram incorporadas a ele? Não me parece uma ideia muito razoável. É aqui, caras e caros, que entra essa bela pilha de papel (ou de não-papel, claro) que vocês têm nas mãos (Trecho do tópico "Prefácio Brasileiro").

Em segundo lugar, assim como no volume original, nossa versão linguisticamente revisada e subversivamente acrescida de um novo tópico - Uma "Bela Apresentação Subvertida" - e republicada pela "AKEDIA Books" (2022), se divide em três partes: Táticas; Princípios e Teorias. Ressaltamos que nosso ponto de partida é uma versão do texto que foi tornada pública no site da Escola de Ativismo e, a partir disto, nos sentimos munidos de uma apócrifa autorização para subverte-la, no que, aliás, seguimos a orientação dos próprios organizadores da obra, atestadas no seu tópico de "Introdução":

Nós convidamos os leitores a explorar nosso site, www.beautifultrouble.org, que é mais do que um apêndice do livro e, talvez represente a expressão mais completa deste projeto. [...] Esperamos que o site cresça e se transforme em uma plataforma em que artistas e ativistas possam convergir para compartilhar ideias, arquivar estudos de caso e debater melhores práticas. Com a participação dos leitores, o conjunto de práticas que constitui o Bela Baderna pode continuar a evoluir e se expandir, acompanhando os movimentos sociais emergentes e suas inovações táticas. Inclusive incluímos modelos de formulários no site para cada tipo de 


\section{AKEDIA}

conteúdo, onde é possível submeter ou sugerir novos módulos. Bela Baderna não é apenas um livro ou um site, mas também uma comunidade cada vez maior de ativistas experientes e artistas que estão usando o conteúdo do livro para treinar a próxima geração de baderneiros.

Nos trechos grifados acima, pode ser que os Organizadores de Bela Baderna tenham dado a entender aos leitores, que sua coletânea aparentemente obedece à índole contemporaneamente consagrada do modelo "wiki", que pressupõe o modelo de produção colaborativa, assim como acontece noutros conteúdos dispostos em repositórios digitais na rede, os quais podem ser livremente acrescidos e compartilhados entre a comunidade de usuários.

Mas, pode ser também, que a maior subversão pública da Escola de Ativismo, tenha sido ofertar Bela Baderna, em regime de distribuição "gratuita". É provável que a Escola de Ativismo, ao agir assim, tenha crido que "liberando" o texto de Bela Baderna ao acesso público, não estaria infringindo coisa alguma, já que estariam "prestando um grande serviço sociocultural à humanidade.

Sob este duplo prisma de possibilidades e em terceiro e último lugar, explicamos que buscamos a versão de Bela Baderna que já estava em regime de acesso público, no site da Escola de Ativismo, e que foi nesta versão pública que fizemos uma revisão linguística, conforme as novas normas do Acordo Ortográfico vigente, corrigindo, inclusive, pequenos erros gramaticais, antes de a republicarmos, acrescida desta Análise.

Em seguida, acrescentamos ao texto, esta "Bela Apresentação Subvertida", recolocando subsequentemente a obra, já diagramada e nestes termos reformulada em repositórios digitais 


\section{$\mathrm{AKED} \cong \mathrm{A}$}

de oferta de conteúdos à comunidade de leitores que por ela viessem a se interessar.

Logo, atendendo ainda ao chamamento coparticipativo que se faz no trecho acima destacado, e como "baderneiro neófito" que me tornei, ao revisarmos, ampliarmos e republicarmos a obra, aplicamos parte do treinamento realizado durante a leitura deste "manual de baderna", dando materialidade ao que ele próprio incita.

Portanto, sob a luz dos termos de seu tópico "PRINCÍPIO: Faça o trabalho da mídia por eles", assinado por Andy Bichlbaum, em que se inscreve uma epígrafe de Jello Biafra - "Não odeie a mídia, torne-se a mídia", nós, da Revista AKEDIA \& AKEDIA Boooks, nos tornamos a própria mídia da subversão prescrita por Jello Biafra, e agora, colocada neste final de obra, Análise proscrita.

E fizemos nesta nossa interpretação apócrifa, além disto, o trabalho de esclarecimento e também de denúncia das apologias negativas que se ensinam na apócrifa Bela Baderna, por nós entendidas como de exposições necessárias à opinião pública.

Estas, supomos, deveriam já ter sido reveladas pela grande mídia que as tivesse divulgado, ou, em plano secundário, pelos tradutores da obra - que com ela tiveram contato íntimo, ou mesmo da Editora que inicialmente o (re)publicou.

Contudo, todos, em cadeia, ao nosso ver, se omitiram, protegidos ou obedientes que se julgavam estar todos sob 0 dulcíssimo Véu de Maya de um questionável viés de liberdade de expressão. 


\section{AKED出}

\section{ANÁLISE APÓCRIFA de BELA BADERNA}

Assim dito, iniciando nossa Análise da obra, e mantendo as divisões originais já mencionadas, vale destacar, que vemos claramente dois momentos distintos na obra.

Um, em que os autores se preocupam em teorizar, descrever e esclarecer o que esta ou aquela linha de raciocínio dispõe ao leitor; e, noutro, os autores dos respectivos Capítulos encartados no volume, em cada uma destas partes, fornecem ao leitor uma espécie de "Orientação" para a "Organização de Grupamentos e de Ação Ativista", a fim de que atuem nos mais diversos segmentos em que se possam estabelecer tais exercícios.

Relembrando o histórico de publicações da obra, vê-se que a Escola de Ativismo brasileira o coeditou (em 2016), dando livre acesso do texto ao público, a ativistas e militantes de todas as causas. Acresceram-se a estes, desde então, "Notas" e "Estudos de Caso", exemplificando o modo com que se deram a aplicação prática das verdadeiras "técnicas de guerrilha" apresentadas no Beatutiful Trouble, em teorias tais, como:

A expressão "Guerrilha Eleitoral" une dois conceitos aparentemente incompatíveis. Ativistas eleitorais trabalham dentro das vias mais aceitáveis e convencionais do Estado, em sua tentativa de reformar o sistema pacificamente. As guerrilhas, no sentido militar, existem nas margens mais afastadas do sistema social, em constante movimento, lançando ataques-surpresa contra o Estado, antes de desaparecer novamente. Esta contradição é o que torna o teatro de guerrilha eleitoral uma carta na manga no repertório de resistência, tanto para o oponente quanto para o ativista (Trecho do tópico "TÁTICA: Teatro de guerrilha eleitoral"). 
A partir disso, tal qual se induz literalmente em seu tópico "Prefácio Brasileiro", a obra se tornou um cultuado "Manual de Estratégias Subversivas" a serviço da atuação política no Brasil.

No contexto político brasileiro contemporâneo, a face mais nítida dessa performance, talvez seja a que se aproxima de uma dessas suas ideias: "Os movimentos vencem, não por se tornarem mais poderosos do que seus oponentes ativos, mas, sim, por removerem a base de apoio desses oponentes" (Fragmento do "PRINCÍPIO: Mude o espectro de aliados"). Neste sentido, os cancelamentos de contas de trabalhadores digitais, os banimentos de usuários de redes sociais, a prisão de simpatizantes do atual Presidente não seriam um modo de "atacar" as bases de apoio político no Brasil?

A aplicação institucional disto talvez a tenhamos no chamado "Inquérito do Fim do Mundo". Por meio de atos monocráticos de Ministros do STF - Supremo Tribunal Federal - tem-se mandado investigar, prender pessoas e bloquear redes sociais que veiculam conteúdos sobre o atual Presidente da República do Brasil, Jair Bolsonaro.

Outro ponto neste embate direto, deu-se pela criação de uma "CPI da COVID-19 no Senado" - Comissão Parlamentar de Inquérito. Nesta, por sua vez, sob o pretexto de investigar a condução da Pandemia, realizaram-se massivos ataques à pessoa de Jair Bolsonaro, os quais superaram enormemente a medida do interesse público das investigações. 


\section{AKEDIA}

Com isto, vale dizer, os nossos excelentíssimos Senadores, não só deixaram de dizer informar ao contribuinte pra onde 0 dinheiro dos impostos estariam indo, como também renegaram os postulados de Bela Baderna, num raríssimo intervalo de lucidez da obra, que propõem aos aprendizes de baderneiros: "Conteste o comportamento, não a pessoa. Seja sensível e promova o diálogo aberto" (Fragmento do tópico "TEORIA: Antiopressão"). Agora, quem pôde acompanhar a CPI da COVID, no Senado, assistiu ao show de horrores que aquilo foi.

Mas, não apenas nestes pontos, o teor mais controverso e radical do ativismo tem se evidenciado, uma vez que Fake News (“Lembre-se: as pessoas respondem a uma história, não pelo fato de ser verdadeira, mas porque é significativa para elas" Fragmento do "PRINCÍPIO: Pense narrativamente), ocupação de espaços ("A lógica de ação de muitas dessas ocupações é a de que as pessoas estão retomando espaços que são seus [...]" Fragmento da "TÁTICA: Ocupação), calote coletivo de obrigações financeiras e outras ilusões antiéticas são textualmente "ensinadas" nestas páginas baderneiras:

É aí que entra o boicote à dívida, um experimento de barganha coletiva para devedores. A ideia é simples: coletivamente, nós paramos de pagar nossas contas aos bancos, até que eles negociem. $E$ já que não podem operar sem o dinheiro desses pagamentos - para empréstimos estudantis, hipotecas ou crédito ao consumidor — os bancos estarão sob severa pressão para negociar (Trecho do tópico "TÁTICA: Boicote à dívida").

Apesar de que alguns conteúdos sugeridos explicitamente expressarem teor nocivo à integridade física de terceiros, à essência íntegra da verdadeira liberdade de expressão, à 
propriedade privada, ao recato e aos bons costumes, de algum modo, a militância e os ativistas se considerariam imunes aos postulados legais e morais que os demais membros da sociedade devem seguir. Fazem do pudor uma questão de valoração comercial (se o crucifixo for "baratinho", tudo bem, podem compra-lo e enfiá-lo onde quiserem) e da indecência um esquete cênico, um artístico "ato de luta" a favor dos "direitos das mulheres" - e será que as mulheres concordam mesmo com isso?:

Os jornalões anunciam a barbárie: estátuas de santas foram quebradas. Um crucifixo foi enfiado, literalmente, no cu. [...] O contexto real, porém, era outro. Em meio a uma manifestação pelos direitos das mulheres, enquanto se realizava a Jornada Mundial da Juventude Católica, estátuas foram quebradas em uma performance artística. A estátua de gesso e o crucifixo de madeira, comprados em lojinhas de presentes pela bagatela de vinte reais (se tanto) não passavam ali de objetos cênicos. Goste-se ou não, as encenações, como aquela, servem como estratégias de luta (Fragmento do trecho "PREFÁCIO BRASILEIRO").

Evocam para si, apesar da contradição escancarada, um monopólio de virtude, fazendo com que o cumprimento de normas Ihes sejam facultativos, isto é, a observância destes princípios de convívio coletivo pode ou não ser atendidos, conforme a conveniência do momento:

Responsabilidade pode ser um conceito assustador para ativistas, mas é melhor pensar sobre isso como um processo proativo que construímos juntos, ao invés de um critério que é ou não atendido. [...] No entanto, a responsabilidade não é nosso objetivo; nosso objetivo é a colaboração. [...] A experiência da Ruckus Society com esse princípio é ilustrativa (Fragmento do trecho "PRINCÍPIO: Aceite a liderança dos mais impactados"). 


\section{AKEDIA}

Assim, alicerçados com substratos teóricos vazios como este, os ativistas, fantasiados e pensando como Peter Pan, saem por aí, relativizando valores institucionais, como se crimes e outras obscenidades fossem atos inconsequentes ou ingredientes insossos para engordar roteiros nas "pegadinhas" de programas de auditório, e que as Leis e a Moral da sociedade organizada fossem meros apêndices de adesão facultativa e que, por isso, podem ser livremente ignorados.

Neste sentido, movidos pela tentação de uma repentina liberdade imaginária daquilo que os oprimiria - num dos casos aventados acima, as dívidas - começam a colocar em prática todo a substância agressiva e potencialmente nociva do livro.

Para eles, os ativistas e oprimidos de algum modo, isso passou a ser um necessário e louvável arroubo criativo, além de isso ser, para eles, um elevado grau de expressão e de resistência, é tática de combate às "injustiças" das quais se julgam vitimizados.

No tópico "TÁTICA: Interrupção Criativa", os autores do Capítulo, inclusive, acenam para com a possibilidade de enfrentamento direto entre manifestantes e seus alvos-algozes. Nisso, cabe ressaltar, os autores que se articulam na Bela Baderna se contradizem quanto à natureza das propostas pretensamente "pacíficas" que postulam, utilizando, levianamente, o aval de grandes nomes do ativismo internacional, para tentar legitimar a ambiguidade velada de seu texto:

Devemos sempre conduzir nossa luta no mais alto plano da dignidade e disciplina. Não devemos permitir que nossos protestos criativos degenerem em violência física. Devemos subir às majestosas alturas de confrontar a força física com a força da alma, incessantemente (Dr. Martin Luther King, Jr.) 


\section{AKEDIA}

(Este fragmento está em forma de epígrafe, no tópico: "PRINCÍPIO: Mantenha a postura não-violenta).

Mas, onde estaria este pretenso pacifismo das táticas ensinadas na Bela Baderna, quando lemos isto e também aquilo? Estariam ocultas na previsibilidade inconsequente e hostil de suas premissas. Será que haveriam segundas intenções, ou não? Quer dizer que se utilizar do nome do Dr. Martin Luther King, Jr. seria somente um efeito cênico, posto que, ao provocar no outro um forte ato de repulsa a quaisquer ofensivas injustas impostas a si, a conta do "revide" seria paga por quem se sentiu ofendido - e isto bastaria para fazer das "agressões" dos ativistas um conjunto de atos pacíficos?

Isso vale tanto para se proteger de ursos quanto para o ativismo: encurralar alguém pode provocar reações violentas. Se sua intenção for eliminar a opção de fugir em um cenário em que as opções são lutar ou fugir, você precisa tomar todas as precauções necessárias para minimizar os riscos para você e seus aliados, caso o oponente resolva vir pra cima (Fragmento do tópico: "PRINCÍPIO: Coloque seu oponente em um dilema de decisão").

Será que certos grupamentos ativistas pressupõem, a partir ou mesmo antes da Bela Baderna, que o restante da sociedade pode ser deliberadamente utilizado como fantoches de seus experimentos sociais, só por que eles acham "bonito" nos ver indo e vindo, fazendo algo ou não, segundo os seus próprios interesses?:

Em 1986, cientistas da computação fizeram um experimento sobre emergência - "onde comportamentos globais complexos podem surgir" sem planejamento e sem programação "a partir da interação de regras locais simples. Eles criaram pássaros virtuais chamados boids. [...] Os pássaros se agruparam em um bando. Conforme o bando se 
aproximava de uma nuvem, ele se dividia em bandos menores, para cada um dos lados, e depois se reagrupava - tudo isso sem que a ideia de um bando tivesse sido programada no sistema. Esse experimento foi uma demonstração nua e crua de algo que vivenciamos na natureza e na sociedade o tempo todo - e algo que os ativistas podem fazer bom uso. Se você está tentando organizar uma obra de arte participativa, uma ação em massa ou uma campanha viral, você não precisa roteirizar tudo - mesmo que você pudesse. Tudo o que você precisa é de algumas regras simples que os participantes possam seguir. Se você estipular as regras certas, elas podem levar a um acontecimento surpreendentemente robusto, eficaz e bonito (Fragmento do "PRINCÍPIO: Regras simples podem levar a ótimos resultados").

Será que o "dilema de decisão" o qual o texto de Bela Baderna tanto enfatiza (a expressão é repetida pelo menos umas 15 vezes na obra resumida), residiria especialmente no fato de que, se quaisquer dos cidadãos que estiverem próximos das intervenções ativistas, se recusarem a atuar como figurantes no seu laboratório sociocultural - então, estes, serão "do contra"; porém, se ficarem quietinhos e cumprirem com seu "papel” de cenário, de mobília útil, então, serão "do bem" - este seria um "dilema de decisão" falso ou verdadeiro? - Não sei - o que vocês acham, desse dilema do "ser" ou não "ser"?:

A ideia de que você possa mudar a cabeça dos malfeitores com uma reunião em massa, na frente do seu reduto, não é exatamente o que mostra o registro histórico. Ao contrário, pense no seu oponente e no público direto como atores involuntários de uma peça de teatro que você está planejando para outra audiência, que eles nem sabem que existe (Fragmento do Tópico: "PRINCÍPIO: Toque para o público que não está lá").

Como exemplo dessa arapuca militante em que o ativismo pueril compulsoriamente nos coloca a todos, temos o fragmento 


\section{AKEDIA}

textual a seguir. Imaginemos, na cena descrita abaixo, do que o ativismo ensinado em Bela Baderna considera como uma "interrupção criativa e não passiva", se o "alvo" da manifestação, em atitude de autodefesa instintiva, estivesse armado ou se lutasse fisicamente com o suposto "manifestante / agressor", o que poderia ter acontecido (a ambos) ainda faria parte do contexto de uma "manifestação criativa", ou algum dos envolvidos (isso vale tanto para os militantes quanto para o seu "alvo) reputaria ser este um ato de grave agressão - "e, neste segundo caso, quem seria responsabilizado pela eventual violência recíproca gerada?:

Uma interrupção criativa não precisa ser passiva. Quando Newt Gingrich veio para a conferência do Conselho da Família de Minnesota, para autografar livros, um ativista gay esperou pacientemente na fila e, quando chegou sua vez, jogou uma bomba de purpurina arco-íris sobre Gingrich, gritando "Sinta o arco-íris, Newt! Chega de ódio, chega de políticas anti-gays", enquanto era retirado da sala. O vídeo documentando 0 evento viralizou (Veja o tópico: PRINCÍPIOS: Faça o trabalho da mídia por eles) e a ação ganhou a atenção da imprensa internacional, provocando uma onda de ativismo LGBT.

Talvez o alvo-algoz nem fosse o escritor Newt Gingrich, ainda que ele próprio, noutros tempos, tivesse manifestado posturas intelectuais distintas daquelas dos indivíduos que o tenham atacado. É provável, enfim, que os verdadeiros alvos nem estivessem na cena, que nem fosse o escritor:

Algumas vezes, ativistas pensam que fazem o que fazem para mudar a cabeça de banqueiros, executivos ou outros aos quais se opõem ostensivamente. Uma coisa é fingir que você faz uma ação para convencê-los - para encenar uma ação teatral eficaz, isso é geralmente necessário - outra coisa completamente diferente é você mesmo acreditar nisso 


\section{$\mathrm{AKED} \cong \mathrm{A}$}

(Fragmento do Tópico: "PRINCíPIO: Toque para o público que não está lá").

Por causa desses vieses de contradição que se levantam frente ao olhar mais atento, é que cremos, assim como muitos que já o leram, que o texto de Bela Baderna virou um tipo de "Manual de Guerrilha Política e Social", que mistura, em si, elementos de um "Manifesto Ativista das Minorias", ao mesmo tempo em que se tornou um "Guia para a Formatação de Pedagogias Subversivas" ou um "Roteiro para o Treinamento de Militâncias e Organização das Massas" (as expressões entre aspas neste parágrafo não são akedianas - tratam-se de impressões de leitura coletadas de terceiros, cujas fontes se perderam pelos ambientes virtuais de reedições da obra).

Não é igualmente contraditório dizer que os ativistas e militantes devem acatar a liderança daqueles que seriam os mais impactados pelas suas intervenções criativas: "Aceitar a liderança dos mais impactados é uma ótima oportunidade para aprender e para apoiar grupos impactados em suas lutas" (Trecho do "PRINCÍPIO: Aceite a liderança dos mais impactados"), se, ao mesmo tempo ignoram que são justamente os Empresários, os Liberais e os Conservadores os alvos do calote às dívidas, da interrupção do expediente comercial, da cessação de lucros em função de greves, que terão o patrimônio vandalizado em quebradeiras e pichações etc.?:

Conhecemos bem a arrogância dos benfeitores liberais aquela que se origina do luxo de poder escolher dentre um cardápio de causas, pois nenhuma delas afeta diretamente sua vida, ou de achar que por ter estudado um assunto na universidade, é um especialista. Evite ser essa pessoa: cultive a humildade e aceite ser guiado e liderado por 


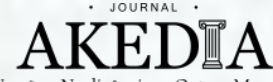

aqueles que serão os maiores afetados por um assunto (PRINCÍPIO: Aceite a liderança dos mais impactados).

Não seria o caso de o ativismo aceitar a liderança dos Empresários, os Liberais e os Conservadores, já que estes seriam, em tese, os mais impactados por muitas de suas ações?

Como exemplo da didática deturpada e perigosa que nas entrelinhas de tais páginas se reverbera, e para compreendermos a dimensão que tudo isso pode assumir, convém revisitarmos os postulados da "Ruckus Society" (fundada por Mike Roselle e Twilly Canno, no Oregon - EUA, em 1995).

Em nome de pautas antibelicistas, ambientais e humanitárias, esta instituição treina, organiza e promove atos de militância, às vezes, até, com nuances de guerrilha urbana e com estímulo à desordem.

No Brasil, a Escola de Ativismo, regida pela premissa "sem lideranças ou hierarquias fixas", filosoficamente ecoa tais fundamentos, o que na Bela Baderna também se recomenda:

Se somos parte de um grupo que se gaba de não ter líderes, os participantes podem hesitar muito em se prontificarem a tomar iniciativa, por medo de serem vistos como um "líder", o que seria uma coisa mal vista. Se queremos realmente mudar o mundo, precisamos de mais pessoas se prontificando a tomar iniciativa, e não menos. Quanto mais iniciativa cada um de nós tomar em nosso trabalho conjunto, maior será nossa capacidade coletiva. Construir nosso poder coletivo é um dos desafios mais importantes da organização de movimentos (Fragmento do "PRINCÍPIO: Somos todos líderes").

Contudo, o que não se leva em conta é que, uma vez, aquela parte da sociedade não tendo exatamente a quem se reportar, caso alguém se sinta ofendido, incomodado ou sofrido algum dano, lança 


\section{$\mathrm{AKED} \cong \mathrm{A}$}

as ações ativistas a um sensível território de ilegalidade. Isto é, ao utilizarem-se abertamente do "anonimato", que, no Brasil, é inconstitucional - https://escoladeativismo.org.br/escola/), a Escola de Ativismo não só age contra a Lei brasileira, como também repercute digitalmente, desde 2011, os fundamentos de treinamento e de organização de eventos da "Ruckus Society", organismo que atua assim, desde 2011.

Na mesma senda, difunde-se, a partir de 2012, outros ditames descritos na Bela Baderna: "Ninguém e todo mundo está no comando. É uma 'coincidência organizada'. E funciona" (Fragmento do "PRINCÍPIO: Regras simples podem levar a ótimos resultados").

Neste sentido, é de se depreender, afinal, que o anonimato de grupos como o "Anonymous" (citado, na Bela Baderna, como "modelo de sucesso, no tópico "TEORIA: Zonas autônomas temporárias (ZAT)", parece ser premissa de grande valor para os baderneiros, e uma das ferramentas de ativismo mais úteis:

$\mathrm{Na}$ sua forma inicial, o conceito tem sido adotado por uma comunidade online descentralizada, atuando de forma anônima, de maneira coordenada, geralmente em torno de um objetivo livremente combinado entre si e voltado principalmente a favor dos direitos do povo perante seus governantes. A partir de 2008, o coletivo Anonymous ficou cada vez mais associado ao hacktivismo [...] (Definição do grupo Anonymous, retirada da WIKPEDIA).

Nesta mesma genealogia de enfrentamentos, registramos o nascimento de organismos de informação e de contrainformação, como o "Sleeping Giant", nos EUA (depois na vitória de Donald Trump, em 2016, o publicitário Matt Rivitz organizou uma ofensiva em redes sociais, com o intuito de bloquear o potente avanço de 
iniciativas de comunicação conservadoras de pessoas físicas e jurídicas.

Fato, é que esta iniciativa deu azo ao que viemos a conhecer, pouco tempo depois, como sendo a "Era dos Cancelamentos" que varreu os sistemas de propaganda de empresas, a monetização de youtubers e a remuneração de trabalhadores digitais das redes sociais no Brasil.

No Brasil, inclusive, ao largo desses aparatos de rebeldia quase ditatorial, tivemos a criação dos chamados "MAVs" (núcleos de Militância em Ambientes Virtuais) e o "Manual do Tuiteiro Petista", iniciativas do Partido dos Trabalhadores (PT) que remontam ao ano de 2012, e que, se não motivadas pelas linhas de Beautitul Trouble, ao menos coincidem com a publicação de Bela Baderna , quando ainda em inglês, constituindo-se, os MAVs, em veículo de repercussão importante dos preceitos baderneiros previstos naquela obra.

O ápice dessa militância digital do PT, contudo, pode ter se materializado, anos depois das "MAVs", na fala de um dos petistas mais proeminentes, José Dirceu, quando este declarou como, por detrás das cortinas, pensaria a nata do lulopetismo mais radical (depois, houve nova matéria, em que Dirceu disse "ter sido infeliz" em sua declaração - mais, aís, já era tarde demais: "É uma questão de tempo pra gente tomar o poder. Aí, nós vamos tomar o poder, que é diferente de ganhar uma eleição" (Entrevista cedida a Marina Rossi, em Recife - PE, 26/09/2018. El País Brasil: https://brasil.elpais.com/brasil/2018/09/24/politica/1537815456 213002.html). 


\section{AKEDIA}

$\mathrm{E}$, é claro, na Bela Baderna, há num dos capítulos, uma dessas "coincidências organizadas", em que esse roteiro radical pode ter se inspirado:

O poder não vem apenas da capacidade de usar a força daqueles que comandam, mas, também, do consentimento e da cooperação daqueles que são comandados, elementos que podem ser voluntariamente e não-violentamente retirados, ao identificar, expor e enfraquecer os "pilares de apoio" de quem comanda - as instituições e organizações que sustentam esse poder (Fragmento do trecho "TEORIA: Pilares de apoio).

E não são apenas estes. Diversos outros grupamentos e organismos multilaterais se dispuseram ao mesmo modus operandi. Por exemplo, o "Black Lives Matter" (movimento ativista marxista internacional, fundado em 2013), cujo início se deu após a absolvição de George Zimmerman, acusado pela morte de Trayvon Martin.

Outro, o "Black Bloc", embora originado na Alemanha, em 1980, tendo passado a atuar no Brasil, em 2000, ganhou visibilidade no país somente em 2013, ao participar de enfrentamentos públicos com a polícia, se infiltrando em movimentos pacíficos, praticando vandalismo e violência. $E$ isso não para por aqui.

Tudo isto nos parece, de algum modo, convergir para a ideologia de estruturas multilaterais, como o "Global Shapers Community" (GSC). Este, por sua vez, outro destes mecanismos multilaterais regidos por propósitos obscuros, fundado pelo presidente executivo do Fórum Econômico Mundial, o Professor Klaus Schwab, em 2011. 


\section{$\mathrm{AKED} \cong \mathrm{A}$}

Dentre as controversas pautas do "Global Shapers Community", estão acabar com as religiões, com a Soberania das Nações e com a propriedade privada e, para alcançar esse alvo, dizem, é necessário o estabelecimento de "causas globais", como a da solidariedade entre os homens, a não ingesta de carne e a alimentação por meio de insetos, o fim da desigualdade social, adesão às políticas de gênero, às pautas identitárias e o combate às mudanças climáticas.

Outra destas instituições que se levantam silenciosamente nas coxias de algum obscurantismo, é a "Open Society Foundation" (OSF). A "OSF" é mantida pelo excêntrico multimilionário húngaroestadunidense, George Soros. Esta instituição angaria fama, tanto pelo volume da filantropia positiva à qual se vincula, quanto pelas suspeitas negativas e ou conspiratórias às quais são associados os seus "investimentos".

Dentre seus empenhos de recursos, estariam o financiamento do extremista brasileiro, Jean Wyllys, pago para estudar "fake news", em Harvard; o financiamento da "ONG Asuntos Del Sur", a qual é responsável, na Argentina, pela "Academia de Innovación Política", entidade coordenada pela extremista Antonella Perini; a participação no financiamento da "ONG Anis Bioética", cuja principal integrante é a ultra feminista e opositora feroz de Bolsonaro, Débora Diniz (ela é uma das mais conhecidas ativistas e defensoras da morte de nascituros).

A "OSF" também patrocina o Fundo Marielle Franco, que tem se dedicado a ações de doutrinação para novas lideranças políticas de extrema esquerda. Além disso, a "OSF" contribui com o funcionamento do "Fact-Checking", organismo atuante no Brasil, 
responsável pela censura e perseguição de certas ideias na internet.

Sob a batuta financeira de Soros, ainda estão a "ONG Avaaz.org", por meio da qual, Alessandra Orofino (Economista, mobilizadora, cofundadora do "Meu Rio", colunista do jornal Folha de S. Paulo e diretora geral do Programa Greg News), fundou a "Purpose NY" (entidade ligada ao ativista Jeremy Heimans), alimentando, por aqui, atos que representam o esforço de adesão de grandes fortunas globais para a mudança social sutil, por meio de permanente propaganda de ideias globalistas e de incentivo ao hacktivismo.

\section{CONCLUSÕES}

Portanto, vejam que não foi à toa, que Shwab publicou, em 2020, o interessantíssimo livro, intitulado "The Great Reset - what's behind the pandemic that disrupts the world" ( $O$ Grande Recomeço - o que está por detrás da pandemia de COVID-19). Aqui na Bela Baderna, escutamos o solene eco de todas as causas que estes movimentos todos defendem, e vemos nas cores de todas as bandeiras a ira que hasteiam:

Dada a urgência de confrontar as "grandes questões" como o poder das corporações, a militarização e a destruição ambiental - o patriarcado e o sexismo dentro de nossos grupos geralmente permanecem deixados de lado. Alguns aliados do sexo masculino sentem que são incapazes de serem machistas; mas simplesmente acreditar na igualdade de gênero não apaga os privilégios masculinos. Se quisermos desafiar o patriarcado, nós precisamos entender como nossas ações e suposições são influenciadas pela 
predominância do sexismo em nossa consciência e nas relações sociais. [...] Acabar com o patriarcado não é apenas uma responsabilidade coletiva - trata-se, em última análise, do crescimento pessoal e interpessoal e da libertação coletiva (Tópico: "PRINCÍPIO: Desafie o patriarcado ao se organizar").
\end{abstract}

Neste contexto, vemos que, num dos tópicos da Bela Baderna que se tem conformado em torno da posologia da bagunça, temos uma pérola do controverso bom senso que os autores de Bela Baderna evocam para si próprios, e que pode soar ao ouvido dos leitores mais radicais da militância e do ativismo, como uma espécie de salvo conduto moral, verdadeira salvaguarda para que ajam sem restrições:

Uma estrutura de ação direta não-violenta estratégica faz com que rejeitar a provocação seja mais fácil. Nós sabemos com o que concordamos - e qualquer um que estimule outras maneiras de agir pode ser lembrado do que foi acordado, ou pode ser rejeitado (Tópico: TÁTICA: Nãoviolência estratégica).

Contudo, ao contrário disso que eles próprios destacam na citação acima, o tema do livro em sua totalidade nos parece ser um suicídio jurídico para quem vier a protagonizar o grosso dos atos "ensinados", visto que a bússola dos caminhos sugeridos, como um todo, ruma às ilegalidades executáveis frente ao Estado e para com os demais membros da sociedade organizada, ainda que pretensamente pacíficas:

Nos organizamos abertamente, sem medo, porque acreditamos em nossas ações. Pode ser que violemos alguma Lei para seguir as Leis superiores da consciência. Não buscamos punição, nem aceitamos o direito do sistema de nos punir, mas encaramos as possíveis consequências de nossas ações com coragem e orgulho (Trecho do tópico "TÁTICA: Não-violência estratégica). 
E é assim, na entrelinha dessas ambiguidades, que coloca o certo e o errado no mesmo nível de igualdade, que nos pareceu que a obra, em primeiro lugar, subverteu a si mesma, ao transformar a joia científica que the havia intrínseca (e que seria o fato mais relevante a ser dela abstraído), em acessório vulgar de loja de bijuterias (que é a versão, a narrativa que deles se tem feito difundir):

Conduza com histórias, não fatos. Fatos raramente falam por si. Apesar da precisão factual da sua mensagem ser essencial, fatos devem servir apenas como detalhes de apoio para a história, e não como gancho que torna a história cativante (Fragmento do "PRINCÍPIO: Mostre, não conte").

Tudo o que a Bela Baderna poderia ser e significar para a produção e difusão do conhecimento científico, a teria feito repousar sobre os fatos, dos quais, aliás, a obra deliberadamente abdicou em nome de uma intencional proposta de adesão às narrativas:

Por mais que queiramos acreditar que os seres humanos sejam atores racionais, que tomem decisões baseadas em uma consideração sóbria dos fatos, a ciência cognitiva nos lembra que somos animais narrativos, que captam o mundo por meio de histórias. Nós tomamos decisões mais com nosso instinto do que com nossa cabeça, e os fatos, sozinhos, raramente são suficientes para mover a opinião pública. Por isso, os atores sociais estão constantemente travando uma "batalha de histórias" para moldar a percepção do público (Fragmento do "PRINCÍPIO: Pense narrativamente).

Mas, a pergunta que ainda precisa de resposta, é a de que se haveria outro propósito na Bela Baderna, que não o de propagar narrativas para "moldar" a sociedade e o mundo à sua imagem desfocada e à semelhança de suas débeis relativizações. 


\section{AKEDIA}

Se a resposta para isto for um "sim", este propósito pode ter ficado modestamente escondido no livro, envergonhado e abrigado atrás de algumas verdades que deturpou: "Expor problemas antes escondidos, pode ser o primeiro e mais importante passo para resolvê-los" (Tópico: "PRINCÍPIO: Torne visível o que é invisível”). Ou ainda, num fragmento do Capítulo que talvez seja o de maior "lucidez", em Bela Baderna:

Grupos ativistas, por vezes, cometem o erro de presumir que a opressão (o exercício injusto de poder ou autoridade) é algo que apenas os outros fazem; que nós somos inerentemente antiopressores, só por causa da nossa intenção de acabar com as estruturas opressivas. Infelizmente, a situação é muito mais complexa e ignoramos essa complexidade, por nossa conta e risco (Fragmento do tópico “TEORIA: Antiopressão").

Este, portanto, poderia ter sido o fio condutor geral do livro, ou ainda até possa ser o seu maior mérito - propor uma autocrítica aos movimentos sociais e projetar luzes no contorno esquizofrênico que fazem ao redor dos fatos - isto serviria para a Bela Baderna, para a Escola de Ativismo, para o Sleeping Giants, para a Ruckus Society, para a OSF, para o PT, para a GSC e para todos os Soros, Dirceus e Orofinos que estiverem por aí.

Porém, convém lembrar: "Ai do mundo, por causa dos escândalos; porque é mister que venham escândalos, mas ai daquele homem por quem o escândalo vem!" (Bíblia: Livro de "Mateus", 18:7) - e Beautiful Trouble não se tornou exceção ao provérbio descrito. Ai dessa obra, pois, por meio dela, muitos escândalos vieram à tona!

$\mathrm{E}$, em última análise, em detrimento desse eventual mérito que o livro teria, o conjunto da obra erra, ao propor a transgressão 
no atacado, como estratégia para o restabelecimento do equilíbrio sociopolítico no varejo. Como revolucionária, deveria propor o roteiro inverso: transgredir no varejo, propondo uma nova arquitetura no atacado - receita básica de uma Revolução.

Mas, como o paradoxo é a pedra filosofal da obra:

Uma cultura que valoriza a liderança saudável também premia a responsabilidade, na qual todos somos responsáveis uns pelos outros. Mas, esse foco na responsabilidade deve andar lado a lado com uma cultura de grupo que valorize a liderança. Caso contrário, podemos desenvolver uma mentalidade de "fogo amigo", na qual gastamos nossa energia podando os outros por tomar a iniciativa (Fragmento do trecho "PRINCíPIO: Somos todos líderes).

Ora, veja-se que, se o que vimos, ao longo de nossa análise, foi a insistência, amplamente documentada, no ensino de uma conduta em que os autores de Bela Baderna evidenciaram o repúdio à responsabilidade e à liderança, como, então, será possível, que militantes e ativistas construam uma "cultura que valorize a liderança saudável", e que "também premiem a responsabilidade", se estes são dois argumentos que eles rejeitam?

Desse modo, quer seja pelo teor dos paradoxos e do conjunto controverso do conteúdo que veicula, quer seja pelo viés dos desconfortos que pode provocar, este Beautitul Trouble traduzido, resumido e multi-subvertido, se torna, aqui nas mãos akedianas, ele próprio, agente e vítima da subversão que a Bela Baderna, em todas as suas versões, preconiza.

OBS.: As REFERÊNCIAS do Artigo já foram apresentadas no transcurso do paper. 